\title{
Functional response of fishers in the Isle of Man scallop fishery
}

\author{
L. G. Murray ${ }^{1,2, *}$, H. Hinz ${ }^{1}$, M. J. Kaiser ${ }^{1}$ \\ ${ }^{1}$ School of Ocean Sciences, College of Natural Sciences, Bangor University, Askew Street, Menai Bridge LL59 5AB, UK \\ ${ }^{2}$ Department of Environment, Food and Agriculture, Thie Slieau Whallian, Foxdale Road, St Johns, \\ Isle of Man IM4 3AS, British Isles
}

\begin{abstract}
To implement effective fisheries management, it is important to understand the variables influencing the distribution and intensity of fishing effort. The functional response of consumers to the availability of prey determines their impact on prey populations. The relationship between predator and prey observed in nature also applies to fishers and the populations they target. The present study focuses on the behaviour of a scallop dredging fleet fishing for Pecten maximus around the Isle of Man during a single fishing season. The functional response was investigated by examining the relationships between catches and fishing effort, scallop abundance and other variables. Scallop abundance was depleted rapidly during the first month of fishing. The increased patchiness of scallops towards the end of the season probably reduced their catchability, but fishers were able to maintain catch rates at intermediate abundance levels. The functional response did not conform to a particular type, but there was latent fishing capacity in the fishing fleet even at the highest levels of abundance. Therefore, reducing the number of vessels would not necessarily reduce fishing mortality unless combined with a reduction in the fishing power of individual vessels.
\end{abstract}

KEY WORDS: Functional response - Pecten maximus • Fisher behaviour - Optimal foraging • Isle of Man · Scallops

\section{INTRODUCTION}

Understanding the variables that influence the foraging decisions of fishers is a prerequisite to implementing effective management strategies that achieve sustainable use of marine resources. The functional response describes the same relationship in ecology as that between prey abundance and catch rates in fisheries science (Johnson \& Carpenter 1994, Eggleston et al. 2008). Relationships between predator and prey populations have been widely described in terms of numerical and functional responses (e.g. Holling 1961, Hassell et al. 1976, Jeschke et al. 2002, Griffen 2009) over both the short term (Caldow \& Furness 2001, Wong \& Barbeau 2005) and long term (Jaksic et al. 1992, Höner et al. 2002). While the numerical response (Solomon 1949) describes the increase in predator numbers with increasing prey densities, the functional response (Solomon 1949) describes the consumption of prey by predators at different prey densities and often takes one of 3 main forms (Holling 1961).

In a type I functional response, the prey consumption rate ( $C=$ number of prey items per total time) increases linearly with prey availability $(N)$ up to a critical level. Thus, the type I functional response model, where $a=$ encounter rate, is simply:

$$
C=a N
$$

This model applies up to a critical value of $N$ above which there is a plateau in $C$ (see Gascoigne \& Lipcius 2004, Jeschke et al. 2004). Holling's type II functional response model, the disc equation (Holling 1959), is based on the assumption that handling time per prey item is constant and that the total feeding time is the sum of time spent searching for prey and handling prey. The type II functional response, where $t=$ handling time per prey item and $a=$ encounter rate, is described by: 


$$
C=\frac{a N}{1+a t N}
$$

Therefore, the type II response is hyperbolic in nature. However, prey capture may be more efficient at higher prey densities. Thus the encounter rate may be expressed as $a N^{2}$, giving a sigmoidal, type III response (Real 1977):

$$
C=\frac{a N^{2}}{1+a t N^{2}}
$$

If attack rate is expressed as $a N^{m}$, then type I, II and III functional responses can be described by the equation:

$$
C=\frac{a N^{m}}{1+a t N^{m}}
$$

where $m$ is a coefficient allowing for variation in encounter rate with prey density. If $m=1$ and $t=0$, the response is type $\mathrm{I}_{i}$ if $m=1$ and $t>0$, the response is type II; and if $m>1$, the response is type III. If $m>1$, the encounter rate varies with $N$, and therefore $a$ becomes the attack rate coefficient (Smout et al. 2010). $t$ and $a$ are assumed to be constant in the basic functional response equations, which in many cases will not be true (Hassell et al. 1976, Caldow \& Furness 2001). The functional response may deviate from the 3 distinct types due to the cost of foraging (Abrams 1982), or other factors, but in any case it is a major determinant of the population dynamics of predator and prey populations (e.g. fishers and targeted species).

The nature of the functional and numerical response of fishers to the target species will determine the potential impact that fishing activity has on the exploited populations. Fisheries management generally involves the restriction of fishing effort spatially, temporally or through technical measures (e.g. mesh size constraints), or limiting landings (e.g. total allowable catches). These restrictions necessarily change fishing patterns, but their effect depends on the other variables influencing the distribution and magnitude of fishing effort, such as the locations of target stocks relative to fishing ports, weather, vessel size, fishers' knowledge, and prior fishing patterns. Therefore, understanding the key drivers of a particular functional or numerical response to prey availability will assist management decisions that aim to achieve conservation of pressure stocks.

A number of studies have examined fisheries in an optimal foraging context. These include studies of both artisanal (Beckerman 1983, Begossi 1992, Béné \& Tewfik 2001) and mechanised (Gillis et al. 1993, Rijnsdorp et al. 2000a,b, Gillis 2003) fisheries. Johnson \& Carpenter (1994) examined fish and angler interactions within a framework of numerical and functional responses. Furthermore, Eggleston et al. (2008) identified the aggregate functional response of fishers in a
Caribbean spiny lobster Panulirus argus fishery and the implications for management. Such an approach would be valuable in identifying appropriate management strategies in other fisheries. The lack of spatiotemporal information of sufficient resolution could prevent such an approach being applied, and a number of the difficulties encountered, such as seasonality, are highlighted by Johnson \& Carpenter (1994). However, with the advent of satellite monitoring of individual vessels, examining the functional response of fishers will become much more widely applicable in the future, and several studies have examined fishing effort using satellite monitoring data (Mills et al. 2007, Lee et al. 2010, Gerritsen \& Lordan 2011). Dynamicstate variable models have been used in fisheries science to examine high-grading (Gillis et al. 1995), targeting decisions (Babcock \& Pikitch 2000) and effort allocation (Poos et al. 2010), but to parameterise such models, it is first necessary to understand which variables influence fisher behaviour.

The present study focused on a scallop dredging fleet that fishes in the waters around the Isle of Man, in the Irish Sea (Fig. 1). Fleet dynamics are relatively simple in that they target only 1 species within the open fishing season, and all vessels within the fishery are fitted with satellite vessel monitoring systems (VMS). Furthermore, the fishery does not usually interact with other species of commercial value and there is no incentive for high-grading (a process whereby a legal catch is discarded in the expectation of catching larger individuals that are more valuable). The method of fishing is also relatively simple. The principal modifications to the dredging technique occur by adjusting tension on sprung tooth bars or by altering vessel speed. Thus, we examined the functional response of fishers in response to changing scallop abundance during a single fishing season and sought to identify the type and primary drivers of the functional response to prey availability.

\section{MATERIALS AND METHODS}

Study area and fishery. The Isle of Man has a territorial sea, extending 12 nautical miles (n miles, $22.2 \mathrm{~km}$ ) from the baseline, with an area of $3965 \mathrm{~km}^{2}$. The great scallop Pecten maximus is targeted around the Isle of Man between 1 November and 31 May. Fishers targeting $P$. maximus did not target other species during the study period. $P$. maximus is generally sedentary but moves to evade predators (Thomas \& Gruffydd 1971). Despite $P$. maximus being fished for several decades (Mason 1957), the species has increased in abundance during recent years (Beukers-Stewart et al. 2005), which is possibly related to warming sea temperature (Shephard et al. 2009). 


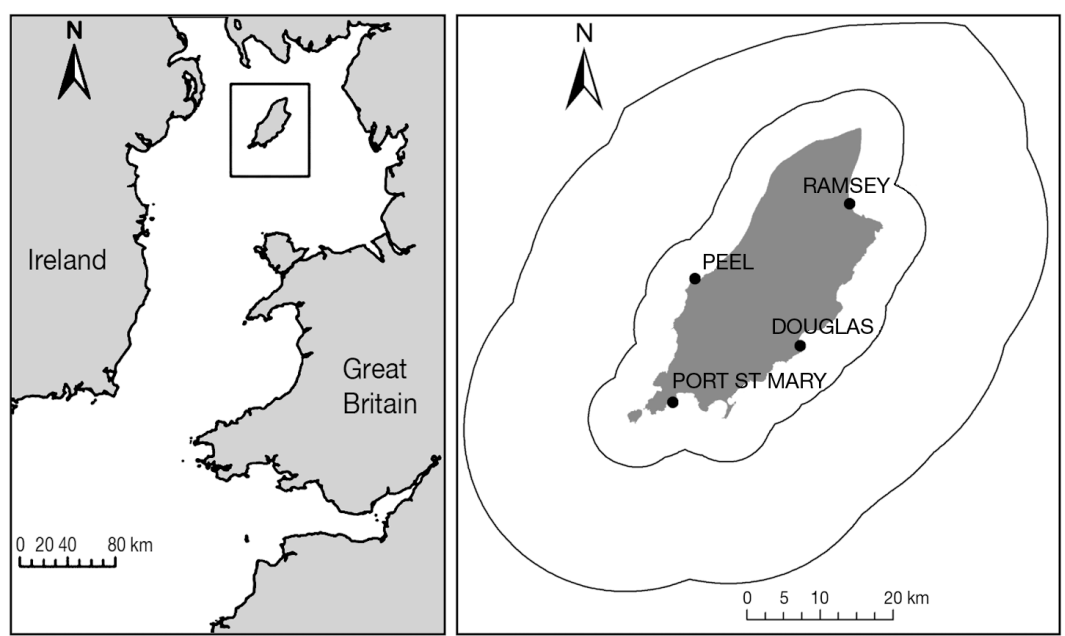

Fig. 1. Isle of Man. Fishing ports and boundaries of the 3 and 12 nautical mile zones are shown

The Isle of Man has exclusive fisheries control out to $3 \mathrm{n}$ miles from its coastline; responsibility for fisheries management is then shared with the UK from 3 out to $12 \mathrm{n}$ miles. Pecten maximus is caught using toothed Newhaven dredges, each of which is $0.76 \mathrm{~m}$ wide. Local fishing regulations during 2007/2008 dictated that a total of 10 dredges per vessel could be used in the inner, 0 to $3 \mathrm{n}$ mile zone, while 16 dredges per vessel could be used in the outer, 3 to $12 \mathrm{n}$ mile zone. During the study period, fishing time was restricted by a curfew to $12 \mathrm{~h} \mathrm{~d}^{-1}$ within the inner zone and $16 \mathrm{~h} \mathrm{~d}^{-1}$ in the outer zone. Fishing for $P$. maximus is prohibited from the beginning of June until the end of October.

The fishery is prosecuted by vessels originating from the Isle of Man as well as by vessels from the UK. The Isle of Man's fishing vessels are based in 4 ports: Douglas, Peel, Port St. Mary and Ramsey (Fig. 1). We focused on fishing activity by the Isle of Man fleet that occurred within the $12 \mathrm{n}$ mile territorial sea, as less comprehensive data are available for other vessels. The great scallop fleet consists of around 25 vessels, although this number varies between years. In this study, data from all 24 Manx vessels known to be fishing during the study period were used. Vessels ranged from 9.23 to $18.4 \mathrm{~m}$ in registered length, with maximum continuous engine power (MCEP) ranging from 60 to $372 \mathrm{~kW}$. Vessels towed between 4 and 8 dredges on each side of the vessel. Toothed bars with 8 teeth of $\sim 110 \mathrm{~mm}$ in length are mounted on a pivot linked to springs. The tension on these springs is usually reduced on cobbly or rocky fishing ground so that less force is required to rotate the tooth bars backwards, reducing the quantity of stones picked up. Once dredges have been hauled, they are emptied onto deck manually by inverting 1 dredge at a time. Once the dredges have been redeployed, or the vessel is steaming, catches can then be sorted. The min- imum landing size for Pecten maximus is $110 \mathrm{~mm}$ at the widest point; thus, smaller scallops are returned to the seabed.

VMS and logbooks. Data were obtained from VMS, which is fitted to all fishing vessels $>15 \mathrm{~m}$ (overall length) in the European Union. However, all dredging vessels operating within $3 \mathrm{n}$ miles of the Isle of Man during the study period were required to have operational VMS transceivers, meaning all Manx vessels were fitted with VMS. UK vessels fishing exclusively between 3 and $12 \mathrm{n}$ miles from the Isle of Man were required to have operational VMS transceivers if they were $>15 \mathrm{~m}$ in length. Consequently, the level of fishing activity by UK vessels $\leq 15 \mathrm{~m}$ in length and not fishing within $3 \mathrm{n}$ miles of the Isle of Man is unknown. Records were received at $\sim 2 \mathrm{~h}$ intervals from all vessels in the study fleet and included latitude and longitude, vessel course and speed recorded using differential global positioning system receivers.

Fisheries logbooks are returned to the Isle of Man Government by all Manx fishers landing to the Isle of Man or UK. UK vessels fishing within the Isle of Man's Territorial Sea and landing catches to the UK submit logbook returns to the UK authorities only, and these were not available for use in this study. Random checks are conducted by fisheries officers to ensure that logbooks have been completed correctly. Logbooks detail gear type and dimensions (i.e. number of dredges used), fishing time and catches for each fishing trip, but do not provide data on catches per tow. Catches are reported in terms of the number of bags of scallops landed. When full, these bags are estimated by fishers and processors to weigh $40 \mathrm{~kg}$. Therefore, the number of bags landed was used in the present study as the unit of catch size. To check that logbooks were representative of actual landings, the reported landings were checked against a sub-sample of landings as recorded by a scallop processor who independently records the number of bags of scallops bought, from whom and on what date, the price paid per $\mathrm{kg}$, and the wet meat weight per bag. Data on landings from 416 fishing trips by 8 vessels landing to 1 processing factory were obtained. Prices were given as $£ \mathrm{~kg}^{-1}$ of meat (adductor muscle and gonad) landed. The prices paid to these vessels were assumed to reflect the prices paid to the entire fleet at any given time. The relationship between the number of bags and the meat weight landed was also examined. Logbook data were linked to VMS data using a unique vessel and date identifier in order to spatially reference reported catches. 
Estimating fishing time. Fishing time vesse $\mathrm{l}^{-1} \mathrm{~d}^{-1}, f_{\mathrm{v}}$ was estimated by plotting the speed frequency distributions of all VMS data from Manx vessels. The speed values falling between the lowest frequency classes on either side of the central mode were examined to identify fishing activity. Thus, the range of fishing speeds was identified as 1.2 to 3.4 knots $\left(\mathrm{kn} ; .2\right.$ to $\left.6.3 \mathrm{~km} \mathrm{~h}^{-1}\right)$. A fishing zone was demarcated around all VMS points indicating a speed of 1.2 to $3.4 \mathrm{kn}$ using a $1 \mathrm{~km}$ buffer; any data points indicating a vessel speed of $<1.2 \mathrm{kn}$ falling within this zone were also considered to indicate fishing activity, as vessels may stop to empty dredges or perform maintenance tasks. Given the $2 \mathrm{~h}$ polling interval, excluding these points would result in underestimates of fishing time. Vessels may at times fish at $>3.4 \mathrm{kn}$; however, it is not possible to distinguish fishing and non-fishing activity at these speeds. $f_{\mathrm{v}}$ was calculated by subtracting the time of the earliest fishing activity $\left(f_{\min }\right)$ from the time of the latest fishing activity $\left(f_{\max }\right)$ for each vessel on each day. Total active time, $T_{\mathrm{A}}$, from first to last VMS record, was calculated by subtracting the minimum time, $T_{\mathrm{A}, \min }$, from the maximum time, $T_{\mathrm{A}, \max }$ as indicated by the first and last VMS records from a fishing trip on any one day. All VMS records were included except those indicating a speed of 0 while in port, as on many occasions VMS transceivers continued transmitting records while vessels were inactive in port.

Fishing times reported in fishing logbooks $\left(f_{1}\right)$ were compared to $f_{\mathrm{v}}$ for each fishing trip. An average of $f_{\mathrm{v}}$ and $f_{1}$ was used as the estimate of fishing time in hours, $f$ :

$$
f=\frac{f_{l}+f_{V}}{2}
$$

If $f_{1}$ was not reported or $f_{\mathrm{v}}$ could not be calculated as there was only a single VMS record, then the alternative measure was used. When $f_{1}$ was not reported and there was a single VMS record only, this was assumed to represent $2 \mathrm{~h}$ of fishing. Where fishing continued outside the territorial sea, $f$ may have exceeded $16 \mathrm{~h}$, although this was rare. Values of $f>16 \mathrm{~h}$ occurred in only 39 fishing trips, and for 21 of these $f \leq 18 \mathrm{~h}$.

The area dredged per fishing trip was defined as:

$$
A=u w f
$$

where $w=$ width of dredges deployed $(\mathrm{km})$ and $u=$ mean vessel fishing speed $\left(\mathrm{km} \mathrm{h}^{-1}\right)$. Therefore, catch per unit effort (CPUE) $=S / A$, where $S=$ number of bags (B) of scallops.

Other variables. The departure and return ports of each vessel fishing trip were determined using a combination of VMS data and fisheries logbooks. A square of $2 \times 2 \mathrm{~km}$ was drawn around each port. When the first or last VMS record fell within any of these boxes, they were deemed to indicate the departure or return ports, respectively. Where no VMS points fell within the port areas, due to a VMS transceiver fault for instance, the departure and return ports recorded in logbooks were used. Cost-distance rasters $(1 \times 1 \mathrm{~km}$ cell size $)$ were generated over the range of fishing activity with each port included as a point source. Thus, in each cell over the range of fishing activity, the distance of that cell from each port was stored. The mean distance of all VMS points defined as fishing activity was then calculated from the appropriate ports using the cost-distance raster files.

UK wave model data (Met Office 2009) was obtained from Met Office hindcast archives and is based on a $12 \mathrm{~km}$ grid at $3 \mathrm{~h}$ intervals. The wave model is forced by wind fields derived from the Met Office numerical weather prediction model and includes swell wave, wind wave, and total wave height, direction and period. The wave data point closest to each VMS record in space and time was associated with that record. Seawater temperature data were derived from mean monthly temperature at Port Erin, Isle of Man (Isle of Man Government Laboratory 2007, 2008). Vessel capacity units (VCUs) were used as a proxy accounting for the differences between vessels, where $\mathrm{VCU}=$ vessel length $\times$ breadth $+(0.45 \times$ engine power $)$ (Pascoe et al. 2003). VCUs were then used to predict the width of fishing gear deployed by vessels from the UK, since no data were available on the actual width of fishing gear deployed by these vessels. Fishing time and the area dredged were calculated as for Manx vessels.

Functional response. Three possible sets of definitions of the time components of the functional response in relation to scallop fishing activity were identified. Firstly, handling time in scallop dredging operations could be considered as the time spent processing each catch unit on deck, $t_{i}$ searching time is then the time spent dredging. Total available time, $T_{\mathrm{T}}$, would then be the $16 \mathrm{~h}$ permitted by the Isle of Man's curfew outside the $3 \mathrm{n}$ mile zone. Transit time, $J$, could be added as an additional parameter or not be considered as part of the functional response. However, no data are available on the time spent handling the catch on deck. A second approach then is to consider handling time per catch unit, $t$, to be equivalent to the time spent dredging and handling the catch on deck (i.e. fishing time per catch unit; thus, $f=S t)$ and the remaining time $(R=$ $T-f$ ) is then the sum of time spent preparing to go to sea, transit, landing the catch and non-fishing activity, where $T_{\mathrm{T}}=24 \mathrm{~h}$. Finally, $T$ may be defined as the total active time as derived from VMS records, $T_{\mathrm{A}}$, and will vary between vessels and days with transit time, $J$, equivalent to searching time. Therefore, the functional response was examined with parameters defined according to the second and third scenarios. 
$C$ is therefore the catch rate per vessel $(C=S / T)$, and the unit of $C$ is $\mathrm{B} \mathrm{V}^{-1} \mathrm{~h}^{-1}$, where $\mathrm{V}=$ vessel, and is distinct from CPUE for which the unit is $\mathrm{B} \mathrm{km} \mathrm{km}^{-2}$. Since $f$ also includes handling time, the area dredged will be over-estimated slightly, although the time spent deploying, hauling and emptying dredges is relatively small compared to the time spent dredging.

Statistical models. Generalised additive models (GAMs) were used to examine the relationship between CPUE and several predictor variables in order to generate a standardised abundance index. A similar approach was used to examine the relationship between $C$ and a range of predictor variables. GAMs were fitted using the 'mgcv' package (see Wood \& Augustin 2002, Wood 2008) in R. Detailed descriptions of the use of the 'mgcv' package and associated methods are given by Wood (2006) and Crawley (2007). GAMs were assessed using the deviance explained and the Akaike information criterion (AIC) and generalised cross validation (GCV) scores.

\section{RESULTS}

\section{Overview of the study fleet}

Total landings of scallops by the study fleet were 25673 bags of great scallops, amounting to $1027 \mathrm{t}$. The Manx fleet swept over $530 \mathrm{~km}^{2}$ of seabed during the fishing season, $13 \%$ of the total area of the territorial sea, although many areas of seabed will have been swept more than once. Over $50 \mathrm{~km}^{2}$ of seabed were swept by the Manx fleet during the first $10 \mathrm{~d}$ of fishing. The general area over which fishing occurred covered $48 \%$ of the territorial sea. Fishing effort was particularly high on the west coast and off the northeast coast, and was higher in inshore areas. Vessels from Port St. Mary, Peel, Ramsey and Douglas fished mean distances of 22.7, 21.3, 20.1 and $17.6 \mathrm{~km}$ from their home ports, respectively.

\section{Fishing time}

The modal fishing speed was $2.4 \mathrm{kn}$ (Fig. 2). Frequency minima below and above the central mode were at 0.2 and $4.8 \mathrm{kn}$; these are outside the normal range of dredging speeds. The effect of setting different upper fishing speeds on estimated fishing time was examined.

When $3.6 \mathrm{kn}$ was used as the maximum vessel speed that was classified as fishing activity, fishing time was over-estimated relative to $f_{1}$ for both mean (Fig. 3a) and total (Fig. 3b) times. Therefore, $3.4 \mathrm{kn}$ was selected as the threshold value.
True fishing time is likely to be underestimated when derived from VMS data, as any fishing activity occurring $<2 \mathrm{~h}$ before the first VMS record or $<2 \mathrm{~h}$ after the last VMS record will be unrecorded. Increasing the value of $f_{\mathrm{v}}$ for each fishing trip by $0.75 \mathrm{~h}$ resulted in a strong correlation with $f_{1}$ for mean (Fig. 3c) and total fleet (Fig. 3d) fishing time, which suggests that $f$ provides a suitable relative measure of fishing time; however, since both $f_{1}$ and $f_{\mathrm{v}}$ may differ from true fishing time, $f$ cannot be considered an absolute measure.

The width of dredges deployed by Manx vessels did not differ significantly between vessels fishing within the $3 \mathrm{n}$ mile zone and those fishing outside of this area, although 5 of the vessels that fished did not fish within the $3 \mathrm{n}$ mile zone. The model including an interaction term (VCU $\times$ zone) was fitted first. Neither the interaction term nor the zone term were significant ( $p \geq 0.726)$, while both the intercept and VCU term were highly significant $(p<0.001)$. Parameters were removed from the model until the lowest AIC was obtained. The final model was the simple linear relationship between VCU and width of dredges, $w_{\text {, }}$ (intercept $=3.705$, slope $=0.029$ ). Hence, the linear relationship between VCU and $w$ was used to estimate the width of dredges deployed by UK vessels.

The difference between $C$ calculated using $T_{\mathrm{T}}$ and $T_{\mathrm{A}}$ was examined using linear regression. There was a strong linear relationship between $C_{T \mathrm{~T}}$ and $C_{T \mathrm{~A}}$ (Fig. 4). Therefore, the proportion of the total time used seemed to have little impact on $C$. Whether $T$ is fixed or included as a variable in the functional response model, the impact will be predominantly on the absolute values of $C$, not the relative values. Hence, $C$ was calculated with $T=24 \mathrm{~h}$.

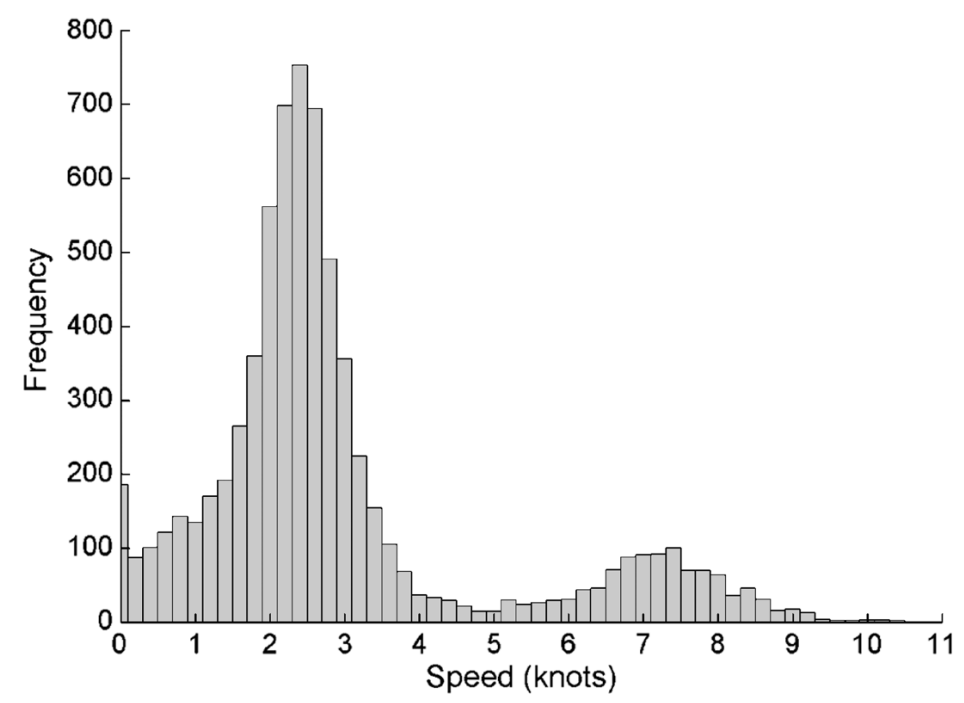

Fig. 2. Vessel speed frequency distribution derived from vessel monitoring system records from the Manx scallop dredging fleet between November 2007 and May 2008 

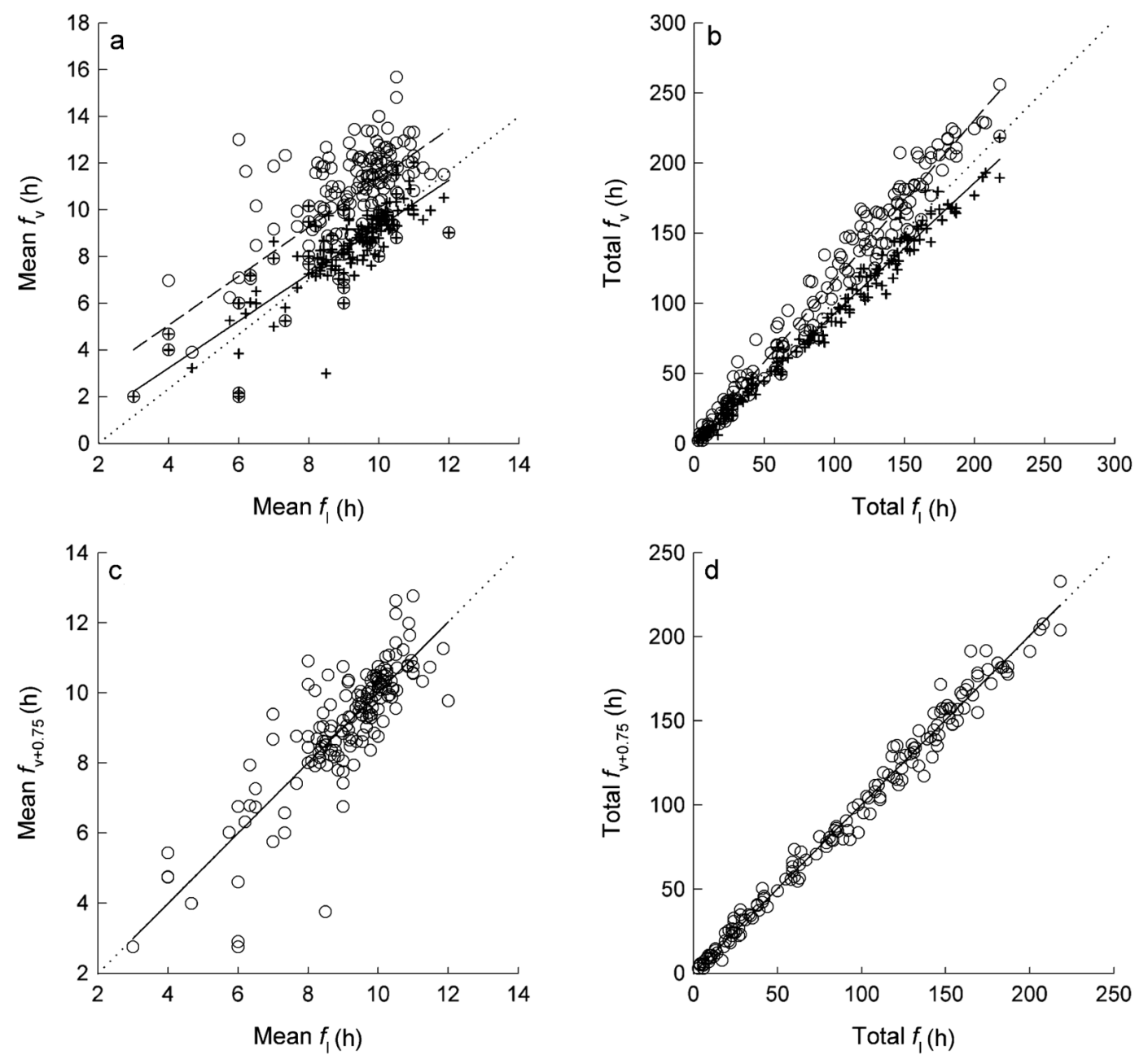

Fig. 3. Relationship between fishing time derived from vessel monitoring system data $\left(f_{\mathrm{v}}\right)$ and fishing logbooks $\left(f_{1}\right)$. Dotted lines show unity between $f_{1}$ and $f_{\mathrm{v}}$ solid and dashed lines are linear regression models. (a) Mean and (b) total daily fishing time when $f_{\mathrm{v}}$ is calculated with an estimated maximum fishing speed of 3.4 knots (crosses) and 3.6 knots (circles). (c) Mean and (d) total daily fishing time when maximum fishing speed was set at 3.4 knots and increased by $0.75 \mathrm{~h}$ to account for underestimation due to the $2 \mathrm{~h}$ polling interval

\section{Abundance}

Several GAMs were fitted to CPUE data and a number of predictor variables. The final model was selected based on the AIC value. The models were fitted to individual fishing trip data using thin plate regression splines. A gamma distribution was used with a log link. Quantile-quantile plots and histograms of residuals showed the distributional assumption to be appropriate, and plots of linear predictors against residuals revealed variance to be approximately constant for all models. Models for which all parameters were significant $(p<$ 0.001) are shown in Table 1. Wave height and mean monthly tempera-
Table 1. Generalised additive models fitted to individual fishing trip data with catch per unit effort (CPUE, bags $\mathrm{km}^{-2}$ ) as the response. Only models for which all terms were significant $(p<0.05)$ are shown. Parameters are: day: time in days from 1 November 2007; $x, y$ : position in degrees of longitude and latitude, respectively; Vessel: factor identifying each vessel. AIC: Akaike information criterion; GCV: generalised cross validation; $s_{i}$ are smooth functions

\begin{tabular}{|llllc}
\hline $\begin{array}{l}\text { Model } \\
\text { name }\end{array}$ & Model & GCV & AIC & $\begin{array}{r}\text { Deviance } \\
\text { explained }\end{array}$ \\
\hline AI1 & $\log (\mathrm{E}[\mathrm{CPUE}])=$ vessel $+s_{1}($ day, $x, y)$ & 0.140 & 13785.88 & 52.8 \\
AI2 & $\log (\mathrm{E}[\mathrm{CPUE}])=$ vessel $+s_{1}($ day $)+s_{2}(x, y)$ & 0.134 & 13735.53 & 53.1 \\
AI3 & $\log (\mathrm{E}[\mathrm{CPUE}])=$ vessel $+s_{1}($ day $)+s_{2}(x)+s_{3}(y)$ & 0.142 & 13849.36 & 49.2 \\
\hline
\end{tabular}




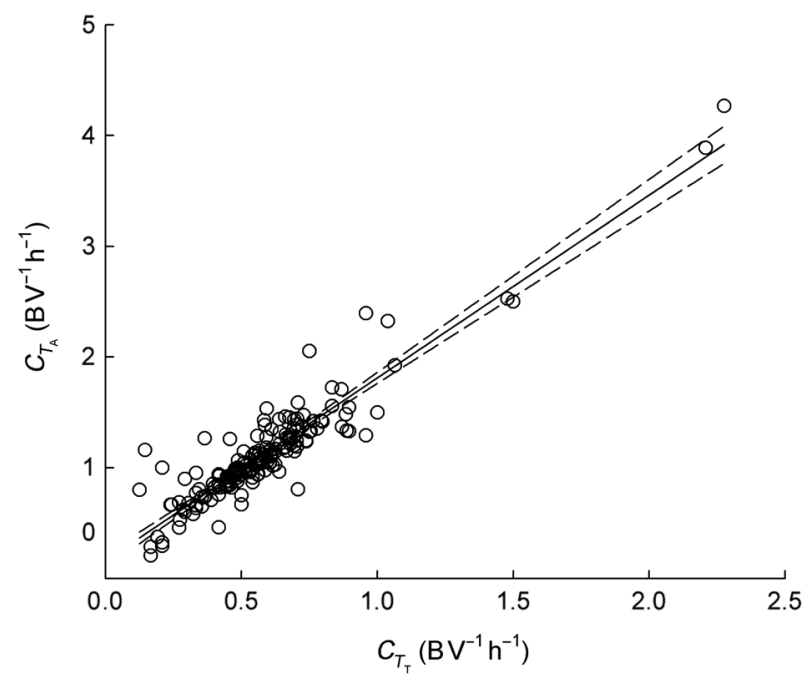

Fig. 4. Relationship between mean daily catch rate $(C$; bags vessel $^{-1}$ hour $^{-1}\left[\mathrm{~B} \mathrm{~V}^{-1} \mathrm{~h}^{-1}\right]$ ) based on total available time $\left(T_{\mathrm{T}}\right)$ and total active time $\left(T_{\mathrm{A}}\right) ; C_{T \mathrm{~A}}=1.651 C_{T \mathrm{~T}}+0.161, \mathrm{R}^{2}=$ $0.87, F_{1,168}=1087.44, \mathrm{p}<0.0001$. Dashed lines indicate $95 \%$ confidence intervals

interaction term and that with a multiple interaction term resulted in higher AIC values. Therefore model AI2 was used to estimate the standardised abundance index, $N$, which is a relative, not absolute, measure of abundance. $N$ declined rapidly during the first $20 \mathrm{~d}$ of fishing, increasing slightly between Days 30 and 50 and thereafter remaining level for $100 \mathrm{~d}$, before declining to a minimum at the end of the season (Fig. 5a). When plotted against $C$ there was a dense cluster of points between an abundance of 28 and 48 with the majority of values of $C<2 \mathrm{~B} \mathrm{~V}^{-1} \mathrm{~h}^{-1}$ at an abundance index $<40$. There was clear acceleration in $C$ above 60 and a plateau in $C$ was not reached (Fig. 5b). Over the first $10 \mathrm{~d}$ of fishing, mean abundance was 82.3 while mean $C$ was $1.24 \mathrm{~B} \mathrm{~V}^{-1} \mathrm{~h}^{-1}$. During the final $10 \mathrm{~d}$ of the season abundance was 28.9 and $C$ was $0.43 \mathrm{~B} \mathrm{~V}^{-1} \mathrm{~h}^{-1}$.

\section{Fishing effort}

Including UK fishing effort, at least $937 \mathrm{~km}^{2}$ were estimated to have been dredged during the fishing season, $109 \mathrm{~km}^{2}$ of this during the first $10 \mathrm{~d}$ of fishing. Fishing intensity by the Manx fleet varied greatly, ranging from $0.1 \mathrm{~km}^{2}$ dredged $\mathrm{km}^{-2}$ to nearly $3 \mathrm{~km}^{2}$ dredged $\mathrm{km}^{-2}$ of seabed. The time spent fishing did not appear to be influenced by market demand, as the time spent fishing averaged over each $10 \mathrm{~d}$ of fishing ranged from 8.1 to $10.7 \mathrm{~h} \mathrm{~d}^{-1}$, with a mean $\pm \mathrm{SD}$ of $9.7 \pm 0.6 \mathrm{~h} \mathrm{~d}^{-1}$. However, the number of vessels fishing varied markedly from a mean (excluding days when no vessels were fishing) of 30 during the first $10 \mathrm{~d}$ of the
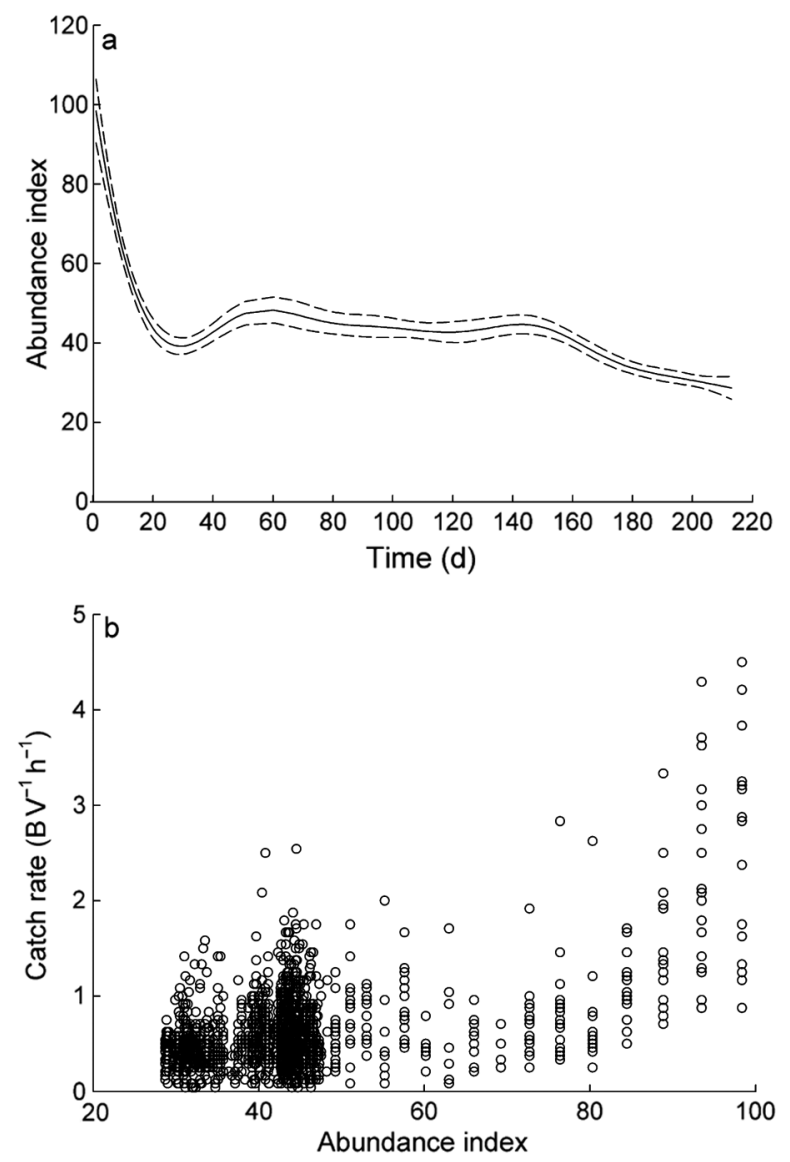

Fig. 5. Pecten maximus. (a) Scallop abundance index $(N)$ over time from 1 November 2007 based on the generalised additive model smooth of the time term (model AI2; see Table 1). Dashed lines indicate $\pm 2 \mathrm{SE}$ of the smooth term. (b) $N$ versus catch rate $(C)$; data points are for individual fishing trips $(\mathrm{n}=1679)$

season to only 3 at the end of December and beginning of January. The maximum number of UK vessels (with VMS) fishing on any one day was 25, while up to 21 Manx vessels fished on any one day.

The price paid for scallop meat varied at certain points during the season, peaking on either side of Christmas (Fig. 6a). There were only 5 main prices paid during the season. Since fishers were paid on the meat weight landed, the yield of scallops may also have had an impact on the number of bags landed. However, despite variation in the meat weight per bag, the relationship between the number of bags landed and the meat weight landed was strongly linear (Fig. 6b). Therefore, fishers did not reduce effort to land fewer bags of scallops when yields were high or land more bags to maximise profit. To examine the combined effects of variation in fishing effort and catchability on the functional response, a second suite of models was fitted to several variables with $C$ as the response variable. 
To describe the relationship between CPUE and $C$, the model must include the parameters used to standardise CPUE, i.e. vessel, day and position (latitude and longitude). These variables may influence the catchability of scallops; in the case of day, the smooth function is assumed to represent $N$. These parameters may also influence $C$ through their effect on fishing effort. Spatio-temporal variation in fishing effort, due to the price paid for scallops or market demand for instance, may occur and thus alter $C$, and the fishing effort exerted by different vessels will also have varied.
Table 2. GAMs fitted to individual fishing trip data with catch rate (bags vessel ${ }^{-1} \mathrm{~h}^{-1}$ ) as response. Only models for which all terms were significant $(p<0.05)$ are shown. Parameters are: day: time in days from 1 November 2007; $x, y$ : position in degrees of longitude and latitude, respectively; $A$ : total estimated area dredged per fishing trip $\left(\mathrm{km}^{2}\right)_{\text {; }}$ VCU: vessel capacity units; $d$ : mean distance fished from departure and return ports $(\mathrm{km}) ; f$ : estimated fishing time $(\mathrm{h})_{i} J$ : estimated transit time $(\mathrm{h})_{;}, w$ : width of dredges deployed (included as a factor with 6 levels); vessel: factor identifying each vessel. AIC: Akaike information criterion; GCV: generalised cross validation

\begin{tabular}{|c|c|c|c|c|}
\hline $\begin{array}{l}\text { Model } \\
\text { name }\end{array}$ & Model & $\mathrm{GCV}$ & AIC & $\begin{array}{l}\text { Deviance } \\
\text { explained }\end{array}$ \\
\hline FR1 & $\log (\mathrm{E}[C])=s_{1}($ day $)+s_{2}(x, y)+S_{3}(A)+$ vessel & 0.124 & -931.53 & 71.4 \\
\hline FR2 & $\log (\mathrm{E}[C])=s_{1}($ day $)+s_{2}(X, y)+s_{3}(A)+s_{4}(\mathrm{VCU})$ & 0.131 & -818.23 & 68.7 \\
\hline FR3 & $\log (\mathrm{E}[C])=s_{1}($ day $)+s_{2}(d)+s_{3}(A)+s_{4}(\mathrm{VCU})$ & 0.156 & -501.53 & 61.8 \\
\hline FR4 & $\log (\mathrm{E}[C])=s_{1}($ day $)+s_{2}(d)+s_{3}(A)+s_{4}(\mathrm{VCU})+s_{5}(x, y)$ & 0.130 & -839.85 & 69.3 \\
\hline FR5 & $\log (\mathrm{E}[C])=s_{1}($ day $)+s_{2}(x, y)+s_{3}(f)+s_{4}(J)+\mathrm{W}$ & 0.116 & -1026.67 & 72.4 \\
\hline FR6 & $\log (\mathrm{E}[C])=s_{1}($ day $)+s_{2}(x, y)+s_{3}(f)+s_{4}(J)+s_{5}(\mathrm{VCU})$ & 0.118 & -994.98 & 71.9 \\
\hline
\end{tabular}

\section{Functional response}

Where fishing time is considered to be handling time, then handling time per catch unit, $t$, is simply a function of CPUE; that is $t=\beta / N$, where $\beta$ is a constant. Substituting $t$ in Eq. (4) and using the abundance index $(N)$, the functional response may be described by:

$$
C=\frac{a N^{m}}{1+a \beta N^{m-1}}
$$
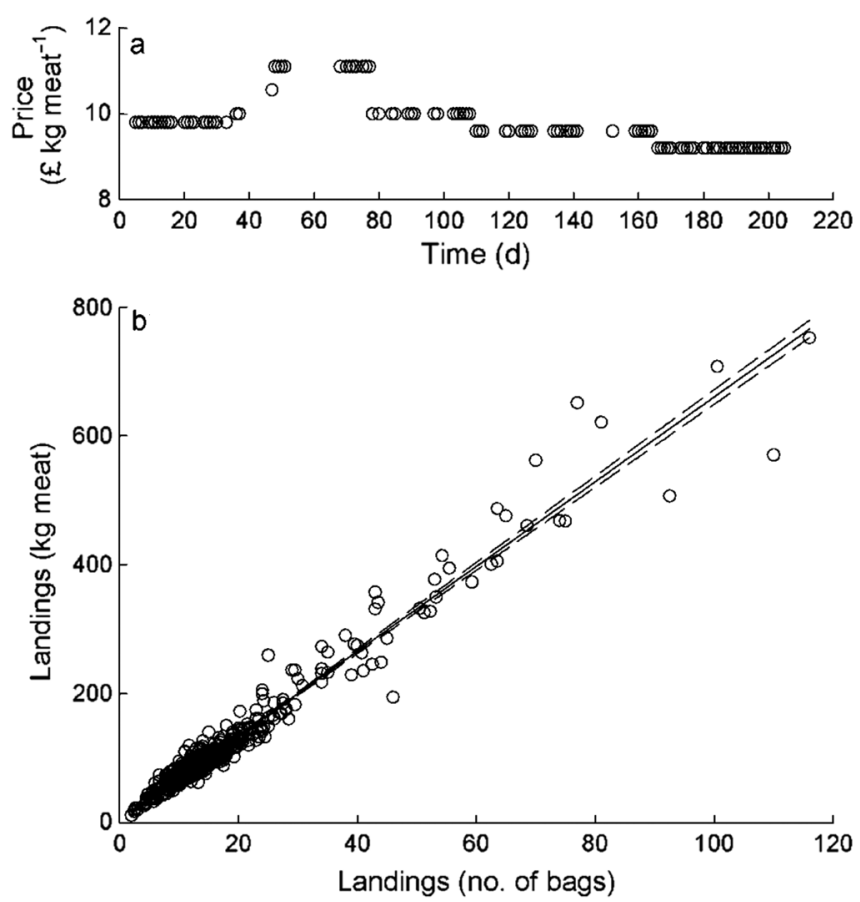

Fig. 6. Pecten maximus. (a) Price paid per kg of meat (gonad + adductor) during the 2007/2008 fishing season, and (b) relationship between the number of bags of scallops landed and meat weight landed. Linear regression: $\mathrm{R}^{2}=0.957, \mathrm{p}<0.0001$, slope $=6.577$, intercept $=3.012$, dashed lines $= \pm 95 \%$ confidence interval. Data derived from 416 fishing trips
Thus, $t$ will not limit $C$ at higher values of $N$, as is apparent in Fig. 5b. However, it is clear from Fig. 5b that this model is inadequate to describe the relationship between $N$ and $C$. Just as CPUE may be a function of several variables other than scallop abundance, the relationship between $N$ and $C$ may be influenced by many variables. The width of fishing gear deployed, hold capacity, weather conditions, seabed type and transit times may all affect catches. To identify the variables affecting $C$, a number of models were fitted including several predictors. Quantile-quantile plots and histograms of residuals were examined to ensure that the distributional assumption was suitable, and plots of linear predictors against residuals revealed variance to be approximately constant for all models. In all cases, the value of $\gamma$ used in the GCV scores was set at 1.4 to avoid over-fitting (Kim \& Gu 2004, Wood 2006) and a gamma distribution was used with a log link function.

Day, position and vessel were included in model FR1 as for model AI2, with the addition of a term for the area dredged (Table 2 ). This model explained $71.4 \%$ of the deviance. Although the vessel term is effective in explaining deviance within the model, the generality of the model is extremely limited with this term and provides no information on why $S$, or $C$, varied between different vessels. VCU reflects the size and fishing power of vessels and therefore may explain differences in catches between vessels. When the vessel term was replaced with the VCU term, the deviance explained by the model (FR2) was reduced to $68.7 \%$ and the AIC increased to -818.2. A potentially important variable that influences the available fishing time, and therefore $S$, is the distance travelled to fish. However, replacing the position $(x, y)$ term with the mean distance fished from the departure and return ports $(d)$ substantially reduced the deviance explained $(61.8 \%)$ and increased the AIC (-501.5; model FR3). Including both position and distance terms increased deviance 
explained (69.3\%) and reduced the AIC (-839.9). An alternative approach would be to replace distance with transit time, $J$. It is then logical to replace area dredged with fishing time, $f$, and the width of dredges deployed (included as a factor with 6 levels). This model explained $72.5 \%$ of deviance and had an AIC of -1030.97 ; however, the VCU term was not significant ( $p=0.09$ ). Removing the VCU term reduced the deviance explained slightly, to $72.4 \%$ and increased the AIC to -1026.67 . These results suggest that VCU is a good proxy for the width of dredges deployed. Replacing the width term with the VCU term reduced the deviance explained to $71.9 \%$ and increased the AIC to -999.98 . Although VCU and dredge width accounted for variability in $C$, there is also likely to be random variation in the catch rates of different vessels that is not related to a vessel's VCU or dredge width deployed. Thus, the final model adopted is a generalised additive mixed model (GAMM) that includes vessel as a random effect
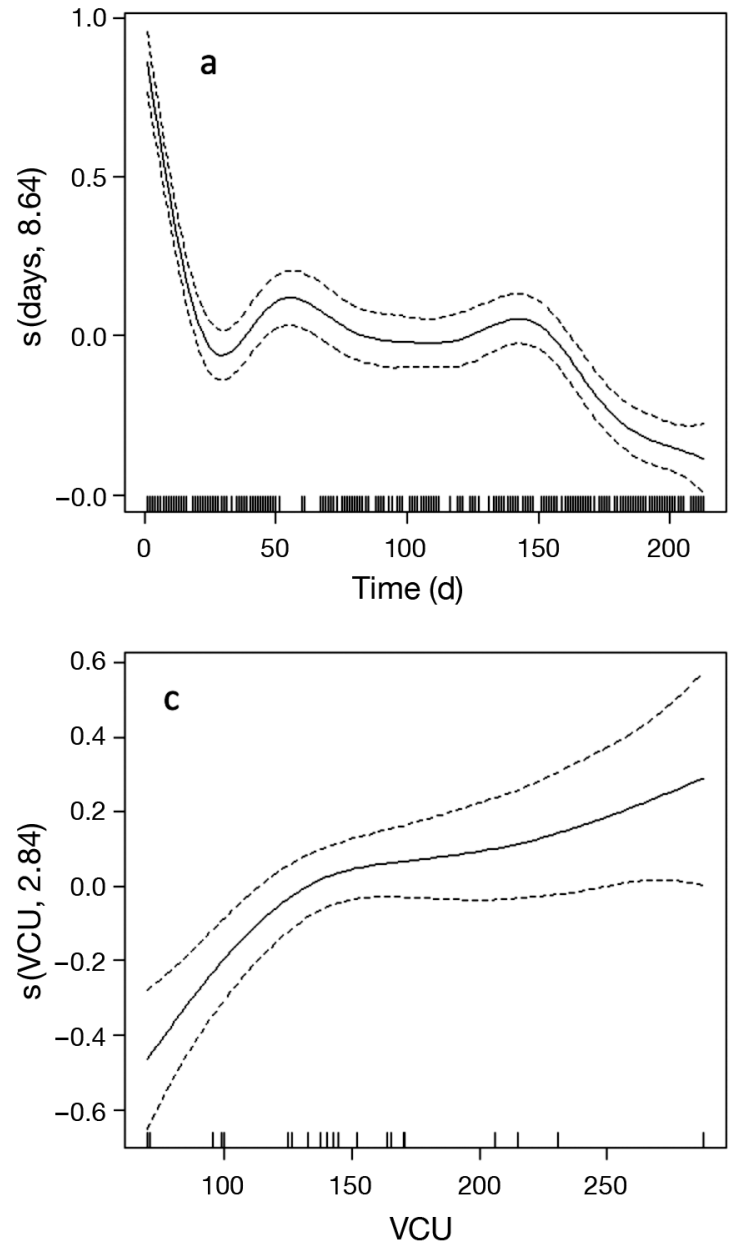

$(e): \log \left(\mathrm{E}[C]=s_{1}(\right.$ day $)+s_{2}\left(x_{1} y\right)+s_{3}(f)+s_{4}(V C U)+J+e$, where parameters are as defined in Table 2. The smooth terms of this model are shown in Fig. 7. The mixed model had an $\mathrm{R}^{2}$ (adj) of 0.671 . Transit time was included as a parametric term, which was found to increase with $C$, showing a very slight exponential increase on the response scale. On the scale of the response variable, time exhibited the same relationship with $C$ (Fig. 7a) as shown in Fig. 5a. $C$ increased with fishing time up to $16 \mathrm{~h}$, thereafter declining slightly (Fig. 7b), and is indicative of the effect of the curfew. It is important to note that $f$ could include some fishing activity from slightly outside the territorial sea, where there is no curfew, which combined with error in the estimates can account for values $>16 \mathrm{~h}$. $C$ increased most rapidly with VCU up to 140 ; thereafter, the rate of increase declined (Fig. $7 \mathrm{c}$ ). The position term indicated peaks in $C$ to the south and northwest of the Isle of Man and the minimum to the northeast
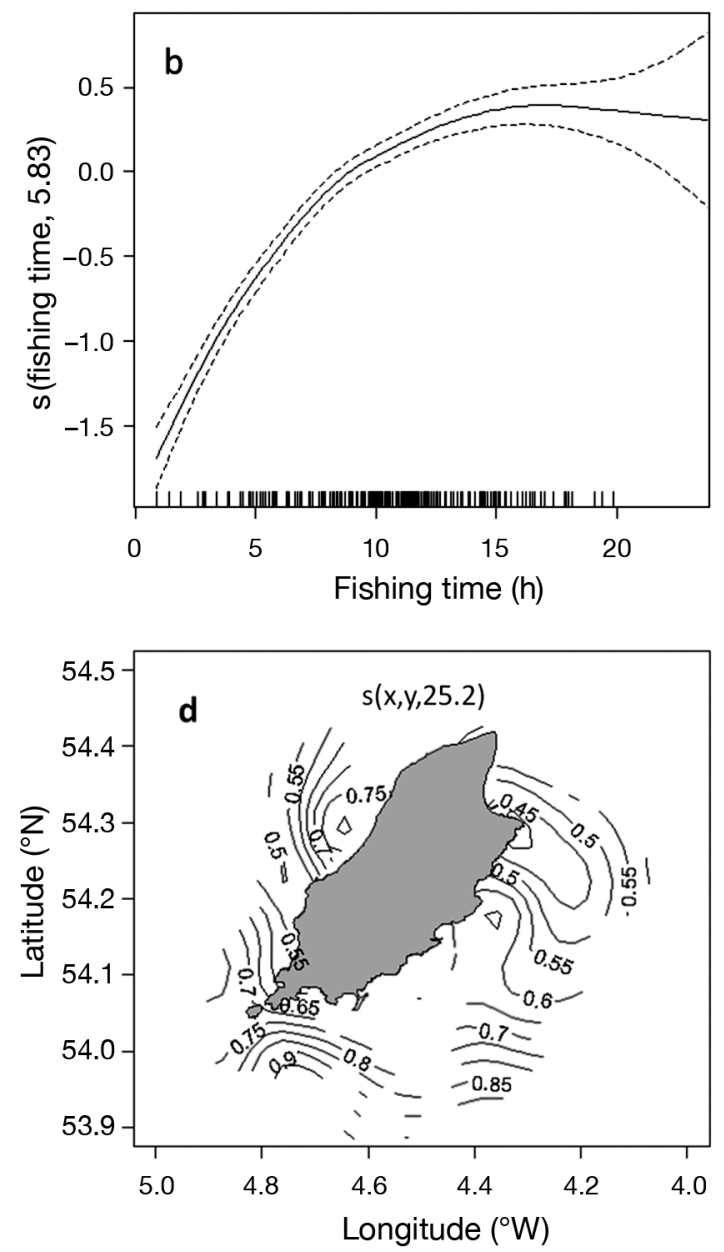

Fig. 7. Estimated smooth terms for the generalised additive mixed model: $\log (\mathrm{E}[C])=s_{1}($ day $\left.)+s_{2}(x, y)+s_{3}(f)+s_{4}(\mathrm{VCU})+J+e\right)$ for catch rate, $C$, in bags vessel ${ }^{-1} \mathrm{~h}^{-1}$, fitted to individual fishing trip data $(\mathrm{n}=1679)$. Vessel is included in the model as a random factor. Plots are on the scale of the linear predictor (log link). Dashed lines indicate \pm 2 SE and include the uncertainty about the overall mean. Estimated degrees of freedom for each term are shown in brackets. (a) Time from Day 0 (1 November 2007).

(b) Time spent fishing. (c) Vessel capacity units. (d) Mean position of each fishing trip 
(Fig. 7d). Whether fishing activity occurred within or outside the $3 \mathrm{n}$ mile zone had no significant effect ( $\mathrm{p}>$ 0.05 ) on catch rates. Replacing the time and VCU terms in the mixed model with area dredged reduced the $\mathrm{R}^{2}$ (adj) to 0.645 and increased the AIC from 1198.7 to 1378.2 .

\section{DISCUSSION}

There are 2 fundamental questions that must be answered to understand fishing behaviour. What influences the spatial and temporal distribution of fishers, and what determines how much fishers catch? Identifying the type of functional response fishers exhibit with changing prey availability can help to answer both questions, but fishing activity is influenced by a number of parameters in addition to prey availability. In the present study, we have examined the relationship between catch rates and several variables relating to fishing effort and catchability.

An important consideration when examining the functional response of fishers is the index of prey availability used. CPUE is commonly used as an index of abundance (e.g. Beukers-Stewart et al. 2003, Maunder \& Punt 2004) but can also be considered as rate of prey consumption (e.g. Johnson \& Carpenter 1994). Simply using mean fleet CPUE does not provide a good index of abundance, as CPUE may become equalised over fished areas as fishers move to maintain catches (Gillis et al. 1993, Gillis 2003). Therefore, it is essential that CPUE is standardised to account for the spatial distribution of the fishing fleet (Sampson 1991). Moreover, fishery-dependent estimates of CPUE may be dependent on the fleet composition at any given time due to variability in fishing efficiency between vessels. CPUE is often standardised with reference to a standard vessel for which a long-term record of CPUE is available (Maunder \& Punt 2004). However, the catches of reference vessels may also be altered by the number of competing vessels and technical advances in competing vessels (Rijnsdorp et al. 2008).

CPUE was standardised to account for vessel differences, for which VCUs were found to be a good proxy. VCUs were also found to explain 70 to $80 \%$ of the variation in earnings of Scottish trawlers (Pascoe et al. 2003). CPUE did broadly parallel the standardised abundance index. However, there were clear differences in CPUE between vessels. Moreover, other variables also influence CPUE. Temperature has a substantial influence on catches of queen scallops Aequipecten opercularis, due to their temperature-dependent escape response (Jenkins et al. 2003). However, Jenkins \& Brand (2001) found no significant effect of season on the number of valve adductions in Pecten maximus following simulated fishing, and there was no clear impact of temperature in the present study. A potentially important variable not included in this study is that of the abundance of under-sized scallops. Although these are not prey to fishers, in that they are not targeted and cannot be legally landed, they may result in fewer scallops of $\geq 110 \mathrm{~mm}$ being caught. If dredges are full, then a greater percentage of undersized scallops will necessarily result in lower CPUE of scallops $\geq 110 \mathrm{~mm}$. Scallop growth stops around December and does not resume until waters warm in March, April or May (Mason 1957). Therefore, changes in the size composition of the scallop population due to growth of scallops will have influenced their catchability at the end of the fishing season in particular. Moreover, it is at this time that the fewest scallops $\geq 110 \mathrm{~mm}$ were available. Dredges can also be filled with other bycatch such as brittlestars, or rocks. These variables may alter the functional response. In particular, the basic functional response equations assume that prey availability, $N$, and handling time per prey item, $t$, remain constant during time, $T$, which in most cases is not true (Hassell et al. 1976, 1977). The meat yield of scallops will also affect their value. High-grading is not thought to occur in the scallop fishery; smaller scallops over the minimum landing size could be discarded in favour of larger, more valuable scallops. However, there would be no advantage to fishers in doing so unless the vessel was nearing maximum catch capacity, which did not appear to occur.

The importance of distinguishing between the forms of functional response is that a type II or III response indicates density-dependent catchability, compared to density independence in a type I response (Eggleston et al. 2008). Furthermore, a type III response can stabilise prey populations (Hassell \& Comins 1978, Nunney 1980, Nachman 2006). However, predatorprey populations do not always conform to a single response type (Jeschke et al. 2004). The results of our study indicate that the functional response of the fishing fleet did not conform to one particular type and that prey density was not high enough for prey consumption to reach a plateau. Therefore, the fishery was not at saturation, with vessels still able to exploit the highest abundance of scallops. It is important to note that almost all values of abundance $>40$ occurred within the first month of fishing, indicating that abundance was depleted rapidly. Fishers' knowledge of scallop distribution may have been greater after the first month of fishing, allowing them to exploit higherdensity patches of scallops to maintain catches. Thereafter, prey consumption rates may have been reduced as prey became increasingly patchy (Essington et al. 2000) towards the end of the fishing season when most areas had been fished. Given that fishers cannot have 
perfect knowledge of the distribution of scallop populations, the chance of a fisher encountering patches of scallops must be reduced at the end of the fishing season.

Previous catch rates are a major influence on the choice of fishing location (Hutton et al. 2004). In the scallop fishery, catches of under-sized scallops in the previous season will provide a good predictor of catches in the following season (Beukers-Stewart et al. 2003) and where fishers have knowledge of areas with high CPUE, they are likely to target them (DreyfusLeón 1999). All of the fishing activity observed in the present study corresponds with historically recognised scallop fishing grounds (Beukers-Stewart et al. 2003). Thus, fishers clearly had some knowledge of the distribution of scallop populations. However, in the scallop fishery, fishing has to be undertaken before CPUE can be determined, unlike other fisheries where sonar can be utilised (e.g. Brehmer et al. 2007, Boswell et al. 2008). Therefore, knowledge of prey distribution will necessarily be imperfect, limiting the numerical response. Moreover, interference competition may prevent fishing in optimal areas (Rijnsdorp et al. 2000a,b). Catches were not obviously suppressed by interference competition in the present study; however, high scallop abundance could mask competitive interactions. Nevertheless, both the number of vessels fishing and catches were highest at the beginning of the season. It is also possible that fishers exerted greater fishing effort when competition was greater.

The rate of deceleration in consumption rates at higher prey densities cannot be predicted; however, it is likely there would be a sharp deceleration either due to satiation (no market demand) or vessels filling their holds to capacity, and the result may be a type I/III response, as described by Jeschke et al. (2004). Type I functional responses have only been reported in filter feeders (Jeschke et al. 2004), while type III responses are often exhibited by generalist predators that can switch between prey species (Van Leeuwen et al. 2007, Kempf et al. 2008). Although scallop dredgers may take bycatch, such as Aequipecten opercularis, the Isle of Man scallop fleet targeted only great scallops during this open scallop fishing season, with queen scallops constituting a very small proportion of total landings, amounting to around $5 \mathrm{t}$ from all vessels during the great scallop fishing season.

It may be possible to refine the analysis of the data used in this study. For example, improved estimates of fishing time may be achieved by adopting methods to reconstruct trawl tracks. Hintzen et al. (2010) used a spline interpolation technique to model fishing tracks from VMS data while Vermard et al. (2010) identified different fishing behaviour during fishing trips, using Bayesian hierarchical models. Moreover, the collection of additional data such as individual tow length and catches per tow would allow more detailed analysis of how fishers respond to changing prey availability. Nevertheless, several conclusions can be drawn from our study.

The assumptions of Holling's disc equation were not appropriate in the Isle of Man scallop fishery. Furthermore, the functional response did not conform very well to a particular type. The increasing patchiness of scallops towards the end of the season probably reduced their catchability, but fishers were able to maintain catch rates at intermediate abundance levels, suggesting knowledge of prey distribution. An important aspect of the observed functional response is that there is latent capacity in the fishing fleet. Eggleston et al. $(2003,2008)$ observed a type I response in a nonsaturated Panulirus argus fishery and therefore concluded that reducing catch limits would be the most effective means of reducing landings. Similarly, setting catch limits or reducing vessels' fishing power together with a reduction in vessel numbers would result in a greater reduction in scallop landings at the highest prey densities, while limiting vessel numbers alone may have little impact. Incorporating additional variables, especially the size composition of scallop populations, into the models presented here will help to further elucidate the relationship between scallop fishers and their prey.

Acknowledgements. This work was funded by the Isle of Man Government Department of Environment, Food and Agriculture, to whom we are grateful; we especially thank A. Read and J. Eaton. Thanks also to W. Caley for providing data on scallop landings. We are also grateful to the Met Office for providing data from the UK wave model, and to the anonymous reviewers whose comments greatly improved the manuscript.

\section{LITERATURE CITED}

Abrams PA (1982) Functional responses of optimal foragers. Am Nat 120:382-390

Babcock EA, Pikitch EK (2000) A dynamic programming model of fishing strategy choice in a multispecies trawl fishery with trip limits. Can J Fish Aquat Sci 57:357-370

Beckerman S (1983) Optimal foraging group-size for a humanpopulation - the case of Bari fishing. Am Zool 23:283-290

Begossi A (1992) The use of optimal foraging theory in the understanding of fishing strategies - a case from Sepetiba Bay (Rio De Janeiro State, Brazil). Hum Ecol 20:463-475

Béné C, Tewfik A (2001) Fishing effort allocation and fishermen's decision making process in a multi-species smallscale fishery: analysis of the conch and lobster fishery in Turks and Caicos Islands. Hum Ecol 29:157-186

Beukers-Stewart BD, Mosley MWJ, Brand AR (2003) Population dynamics and predictions in the Isle of Man fishery for the great scallop (Pecten maximus, L.). ICES J Mar Sci 60:224-242

Beukers-Stewart BD, Vause BJ, Mosley MWJ, Rossetti HL, 
Brand AR (2005) Benefits of closed area protection for a population of scallops. Mar Ecol Prog Ser 298:189-204

Boswell KM, Wilson MP, Cowan JH (2008) A semiautomated approach to estimating fish size, abundance, and behavior from dual-frequency identification sonar (DIDSON) data. N Am J Fish Manag 28:799-807

> Brehmer P, Georgakarakos S, Josse E, Trygonis V, Dalen J (2007) Adaptation of fisheries sonar for monitoring schools of large pelagic fish: dependence of schooling behaviour on fish finding efficiency. Aquat Living Resour 20:377-384

Caldow RWG, Furness RW (2001) Does Holling's disc equation explain the functional response of a kleptoparasite? J Anim Ecol 70:650-662

Crawley MJ (2007) The R book. Wiley-Blackwell, Chichester Dreyfus-León MJ (1999) Individual-based modelling of fishermen search behaviour with neural networks and reinforcement learning. Ecol Model 120:287-297

Eggleston DB, Johnson EG, Kellison GT, Nadeau DA (2003) Intense removal and non-saturating functional responses by recreational divers on spiny lobster Panulirus argus. Mar Ecol Prog Ser 257:197-207

Eggleston DB, Parsons DM, Kellison GT, Plaia GR, Johnson EG (2008) Functional response of sport divers to lobsters with application to fisheries management. Ecol Appl 18: $258-272$

Essington TE, Hodgson JR, Kitchell JF (2000) Role of satiation in the functional response of a piscivore, largemouth bass (Micropterus salmoides). Can J Fish Aquat Sci 57:548-556

Gascoigne JC, Lipcius RN (2004) Allee effects driven by predation. J Appl Ecol 41:801-810

Gerritsen H, Lordan C (2011) Integrating vessel monitoring systems (VMS) data with daily catch data from logbooks to explore the spatial distribution of catch and effort at high resolution. ICES J Mar Sci 68:245-252

Gillis DM (2003) Ideal free distributions in fleet dynamics: a behavioral perspective on vessel movement in fisheries analysis. Can J Zool 81:177-187

Gillis DM, Peterman RM, Tyler AV (1993) Movement dynamics in a fishery - application of the ideal free distribution to spatial allocation of effort. Can J Fish Aquat Sci 50: 323-333

Gillis DM, Pikitch EK, Peterman RM (1995) Dynamic discarding decisions - foraging theory for high-grading in a trawl fishery. Behav Ecol 6:146-154

Griffen BD (2009) Consumers that are not 'ideal' or 'free' can still approach the ideal free distribution using simple patch-leaving rules. J Anim Ecol 78:919-927

> Hassell MP, Comins HN (1978) Sigmoid functional responses and population stability. Theor Popul Biol 14:62-67

> Hassell MP, Lawton JH, Beddington JR (1976) Components of arthropod predation. 1. Prey death-rate. J Anim Ecol 45: 135-164

> Hassell MP, Lawton JH, Beddington JR (1977) Sigmoid functional responses by invertebrate predators and parasitoids. J Anim Ecol 46:249-262

> Hintzen NT, Piet GJ, Brunel T (2010) Improved estimation of trawling tracks using cubic Hermite spline interpolation of position registration data. Fish Res 101:108-115

Holling CS (1959) Some characteristics of simple types of predation and parasitism. Can Entomol 91:163-182

> Holling CS (1961) Principles of insect predation. Annu Rev Entomol 6:163-182

> Höner OP, Wachter B, East ML, Hofer H (2002) The response of spotted hyaenas to long-term changes in prey populations: functional response and interspecific kleptoparasitism. J Anim Ecol 71:236-246

Hutton T, Mardle S, Pascoe S, Clark RA (2004) Modelling fish- ing location choice within mixed fisheries: English North Sea beam trawlers in 2000 and 2001. ICES J Mar Sci 61:1443-1452

Isle of Man Government Laboratory (2007) Marine monitoring 2007. Isle of Man Government, Isle of Man

Isle of Man Government Laboratory (2008) Marine monitoring summary 2008. Isle of Man Government, Isle of Man

Jaksic FM, Jimenez JE, Castro SA, Feinsinger P (1992) Numerical and functional response of predators to a longterm decline in mammalian prey at a semiarid neotropical site. Oecologia 89:90-101

Jenkins SR, Brand AR (2001) The effect of dredge capture on the escape response of the great scallop, Pecten maximus (L.): implications for the survival of undersized discards. J Exp Mar Biol Ecol 266:33-50

> Jenkins SR, Lart W, Vause BJ, Brand AR (2003) Seasonal swimming behaviour in the queen scallop (Aequipecten opercularis) and its effect on dredge fisheries. J Exp Mar Biol Ecol 289:163-179

> Jeschke JM, Kopp M, Tollrian R (2002) Predator functional responses: discriminating between handling and digesting prey. Ecol Monogr 72:95-112

- Jeschke JM, Kopp M, Tollrian R (2004) Consumer-food systems: why type I functional responses are exclusive to filter feeders. Biol Rev Camb Philos Soc 79:337-349

Johnson BM, Carpenter SR (1994) Functional and numerical responses: a framework for fish-angler interactions? Ecol Appl 4:808-821

Kempf A, Floeter J, Temming A (2008) Predator-prey overlapinduced Holling type III functional response in the North Sea fish assemblage. Mar Ecol Prog Ser 367:295-308

Kim YJ, Gu C (2004) Smoothing spline Gaussian regression: more scalable computation via efficient approximation. J R Stat Soc Ser B Stat Methodol 66:337-356

Lee J, South AB, Jennings S (2010) Developing reliable, repeatable, and accessible methods to provide highresolution estimates of fishing-effort distributions from vessel monitoring system (VMS) data. ICES J Mar Sci 67: 1260-1271

Mason J (1957) The age and growth of the scallop, Pecten maximus (L), in Manx waters. J Mar Biol Assoc UK 36: 473-492

Maunder MN, Punt AE (2004) Standardizing catch and effort data: a review of recent approaches. Fish Res 70:141-159

Met Office (2009) UK waters wave model. Met Office, Exeter

Mills CM, Townsend SE, Jennings S, Eastwood PD, Houghton CA (2007) Estimating high resolution trawl fishing effort from satellite-based vessel monitoring system data. ICES J Mar Sci 64:248-255

> Nachman G (2006) A functional response model of a predator population foraging in a patchy habitat. J Anim Ecol 75: 948-958

Nunney L (1980) The influence of the type-3 (sigmoid) functional-response upon the stability of predator-prey difference models. Theor Popul Biol 18:257-278

Pascoe S, Kirkley JE, Greboval D, Morrison-Paul CJ (2003) Measuring and assessing capacity in fisheries. 2. Issues and methods. FAO Fish Tech Pap 433/2. FAO, Rome

Poos JJ, Bogaards JA, Quirijns FJ, Gillis DM, Rijnsdorp AD (2010) Individual quotas, fishing effort allocation, and over-quota discarding in mixed fisheries. ICES J Mar Sci 67:323-333

Real LA (1977) Kinetics of functional response. Am Nat 111: 289-300

Rijnsdorp AD, Dol W, Hoyer M, Pastoors MA (2000a) Effects of fishing power and competitive interactions among vessels on the effort allocation on the trip level of the Dutch 
beam trawl fleet. ICES J Mar Sci 57:927-937

Rijnsdorp AD, Broekman PLV, Visser EG (2000b) Competitive interactions among beam trawlers exploiting local patches of flatfish in the North Sea. ICES J Mar Sci 57:894-902

Rijnsdorp AD, Poos JJ, Quirijns FJ, Hille Ris Lambers R, Wilde JWD, Heijer WMD (2008) The arms race between fishers. J Sea Res 60:126-138

Sampson DB (1991) Fishing tactics and fish abundance, and their influence on catch rates. ICES J Mar Sci 48:291-301

Shephard S, Beukers-Stewart B, Hiddink JG, Brand AR, Kaiser MJ (2009) Strengthening recruitment of exploited scallops Pecten maximus with ocean warming. Mar Biol 157:91-97

Smout S, Asseburg C, Matthiopoulos J, Fernandez C, Redpath S, Thirgood S, Harwood J (2010) The functional response of a generalist predator. PLoS ONE 5:e10761

Solomon ME (1949) The natural control of animal populations. J Anim Ecol 18:1-35

Thomas GE, Gruffydd LD (1971) Types of escape reactions elicited in scallop Pecten maximus by selected sea-star species. Mar Biol 10:87-93

Submitted: April 27, 2010; Accepted: January 31, 2011
Van Leeuwen E, Jansen VAA, Bright PW (2007) How population dynamics shape the functional response in a onepredator-two-prey system. Ecology 88:1571-1581

> Vermard Y, Rivot E, Mahevas S, Marchal P, Gascuel D (2010) Identifying fishing trip behaviour and estimating fishing effort from VMS data using Bayesian Hidden Markov Models. Ecol Model 221:1757-1769

Wong MC, Barbeau MA (2005) Prey selection and the functional response of sea stars (Asterias vulgaris Verrill) and rock crabs (Cancer irroratus Say) preying on juvenile sea scallops (Placopecten magellanicus (Gmelin)) and blue mussels (Mytilus edulis Linnaeus). J Exp Mar Biol Ecol $327: 1-21$

Wood SN (2006) Generalized additive models: an introduction with R. Chapman \& Hall/CRC, London

> Wood SN (2008) Fast stable direct fitting and smoothness selection for generalized additive models. J R Stat Soc Ser B Stat Methodol 70:495-518

Wood SN, Augustin NH (2002) GAMs with integrated model selection using penalized regression splines and applications to environmental modelling. Ecol Model 157:157-177

Proofs received from author(s): March 25, 2011 